\title{
High-Dose, but Not Low-Dose, Aspirin Impairs Anticontractile Effect of Ticagrelor following ADP Stimulation in Rat Tail Artery Smooth Muscle Cells
}

\author{
Grzegorz Grześk, ${ }^{1,2}$ Marek Kozinski, ${ }^{2}$ Udaya S. Tantry, ${ }^{3}$ Michal Wicinski, ${ }^{1}$ \\ Tomasz Fabiszak, ${ }^{2}$ Eliano P. Navarese, ${ }^{2}$ Elzbieta Grzesk, ${ }^{4}$ Young-Hoon Jeong, ${ }^{5}$ \\ Paul A. Gurbel, ${ }^{3}$ and Jacek Kubica ${ }^{2}$ \\ ${ }^{1}$ Department of Pharmacology and Therapeutics, Collegium Medicum, Nicolaus Copernicus University, 9 Sklodowskiej-Curie Street, \\ 85-094 Bydgoszcz, Poland \\ ${ }^{2}$ Department of Cardiology and Internal Medicine, Collegium Medicum, Nicolaus Copernicus University, 9 Sklodowskiej-Curie Street, \\ 85-094 Bydgoszcz, Poland \\ ${ }^{3}$ Sinai Center for Thrombosis Research, Sinai Hospital of Baltimore, 2401 West Belvedere Avenue, Baltimore, MD 21215, USA \\ ${ }^{4}$ Department of Pediatric Hematology and Oncology, Collegium Medicum, Nicolaus Copernicus University, \\ 9 Sklodowskiej-Curie Street, 85-094 Bydgoszcz, Poland \\ ${ }^{5}$ Division of Cardiology, Department of Internal Medicine, Gyeongsang National University Hospital, 79 Gangnam-ro, \\ Jinju, Gyeongsangnam-do 660-702, Republic of Korea
}

Correspondence should be addressed to Grzegorz Grześk; ggrzesk@cm.umk.pl

Received 2 March 2013; Accepted 13 May 2013

Academic Editor: Jeffrey L. Anderson

Copyright (C) 2013 Grzegorz Grześk et al. This is an open access article distributed under the Creative Commons Attribution License, which permits unrestricted use, distribution, and reproduction in any medium, provided the original work is properly cited.

Objective. To compare effects of low- versus high-dose aspirin coadministered with ticagrelor on the reactivity of vascular smooth muscle cells (VSMCs). Methods. Wistar rats were orally administered ticagrelor $(10 \mathrm{mg} / \mathrm{kg})$ and/or aspirin $(2 \mathrm{or} 10 \mathrm{mg} / \mathrm{kg})$ ( $n=7$ per each of 4 groups) or placebo $(n=9) 12$ and 2 hours before experiments. Anticontractile effects of ticagrelor were assessed in perfusion solution containing ticagrelor $(1 \mu \mathrm{M} / \mathrm{L})$. Changes in perfusion pressure proportional to the degree of adenosine diphosphate analogue- (2-MeS-ADP-) and phenylephrine-induced constriction of rat tail arteries were evaluated. Results. Pretreatment with high- but not low-dose aspirin enhanced the reactivity of VSMCs only in endothelium-lined vessels. Suppression of 2-MeS-ADP-induced VSMC contraction by ticagrelor observed in arteries with and without endothelium was maintained in endothelialized arteries pretreated only with low-dose aspirin. For endothelium-denuded vessels and low-dose aspirin we observed a significant reduction of the maximal effect of ticagrelor with no rightward shift of the concentration-response curve for phenylephrine. With high-dose aspirin pretreatment ticagrelor exerted no anticontractile effect. Conclusion. High-dose, but not low-dose, aspirin impairs the anticontractile effect of ticagrelor on ADP-induced VSMC contraction in the rat model. Both the clinical significance and detailed underlying mechanism of our findings require further investigation.

\section{Introduction}

Novel platelet $\mathrm{P} 2 \mathrm{Y}_{12}$ receptor inhibitors, prasugrel and ticagrelor, have successfully overcome many pharmacodynamic limitations of clopidogrel and improved outcomes of patients with acute coronary syndromes (ACS) [1-4]. Therefore both ticagrelor and prasugrel have been approved in Europe and in the United States, and their use in the setting of ACS is currently recommended by international guidelines $[5,6]$.

Ticagrelor is a nonthienopyridine, direct $\mathrm{P}_{2} \mathrm{Y}_{12}$ blocker that is more potent than clopidogrel and is associated with less interindividual variability in pharmacodynamic effect [7]. Furthermore, important characteristics of ticagrelor, such as rapid onset of action and reversible binding to the $\mathrm{P} 2 \mathrm{Y}_{12}$ 
receptor, may lead to improved outcomes and potentially less bleeding in the setting of urgent surgery.

Substantial reductions in major adverse cardiovascular events and all-cause mortality without significantly increased overall major bleeding complications were observed in the PLATO trial, a landmark phase III study comparing ticagrelor with clopidogrel in a broad spectrum of ACS patients [2]. The unprecedented mortality benefits observed in the PLATO trial, despite only a moderate decrease in the occurrence of myocardial infarction, led to a speculation that ticagrelor therapy was associated with off-target effects [8]. Since P2 $\mathrm{Y}_{12}$ receptors were identified on vascular smooth muscle cells (VSMCs) [9], we and others have earlier demonstrated in animal and human models that ticagrelor, but not clopidogrel and prasugrel, prevents ADP-induced VSMC contraction $[10,11]$. Additionally, other groups have demonstrated that ticagrelor inhibited the uptake of adenosine by human erythrocytes [12] and also induced the release of adenosine triphosphate from human erythrocytes, that is, followed by its degradation to adenosine [13]. The former mechanism was proposed to explain the enhancement of adenosine-induced increase in coronary blood flow observed in a canine model by ticagrelor [12].

A substantial geographic variation in ticagrelor efficacy was observed in the PLATO trial [14]. Based on the results of two independent analyses, it was hypothesized that differences in the maintenance dose of aspirin were responsible for this regional difference. In the subgroup of patients treated with high-dose aspirin (at least $300 \mathrm{mg}$ ) in the PLATO trial, particularly in those enrolled in the United States, ticagrelor therapy was paradoxically associated with worse clinical outcomes than clopidogrel therapy [14]. As a consequence of this observation, the US Food and Drug Administration approved ticagrelor with a "Boxed Warning" indicating that aspirin daily maintenance doses of above $100 \mathrm{mg}$ decrease its effectiveness [15].

We compared effects of low-dose versus high-dose aspirin coadministered with ticagrelor on the reactivity of VSMCs in a rat model in this study.

\section{Materials and Methods}

2.1. Animals. The experiments were performed on isolated, perfused Wistar rat tail arteries. Animals were housed under a $12 \mathrm{~h}$ light $/ 12 \mathrm{~h}$ dark cycle and had unlimited access to food and water. Rats $(n=37)$ weighing $250-350$ g were pretreated with investigated drugs ( $n=7$ per each of 4 groups) or placebo $(n=9)$, anesthetized by intraperitoneal injection of $120 \mathrm{mg}$ urethane per $1 \mathrm{~kg}$ of body mass, stunned, and then sacrificed by cervical dislocation. The study protocol was approved by the Local Ethics Committee, and all experiments were carried out in accordance with the United States NIH guidelines [16].

2.2. Drugs and Solutions. The study drugs (ticagrelor and aspirin) or placebo (normal saline) was administered orally 12 and 2 hours before the experiment. Similar to previous studies $[10,11]$, the doses were ticagrelor $(10 \mathrm{mg} / \mathrm{kg})$ and aspirin $(2 \mathrm{mg} / \mathrm{kg}$ or $10 \mathrm{mg} / \mathrm{kg})$. The doses of ticagrelor and aspirin $(2 \mathrm{mg} / \mathrm{kg})$ were equivalent to typical antiplatelet doses in human, whereas the dose of aspirin $(10 \mathrm{mg} / \mathrm{kg})$ was comparable to the anti-inflammatory and antipyretic dose used in human studies. Krebs solution contained $\mathrm{NaCl}$ (71.8 $\mathrm{mmol} / \mathrm{L}), \quad \mathrm{KCl}(4.7 \mathrm{mmol} / \mathrm{L}), \mathrm{CaCl}_{2} \quad(1.7 \mathrm{mmol} / \mathrm{L})$, $\mathrm{NaHCO}_{3}(28.4 \mathrm{mmol} / \mathrm{L}), \mathrm{MgSO}_{4}(2.4 \mathrm{mmol} / \mathrm{L}), \mathrm{KH}_{2} \mathrm{PO}_{4}$ $(1.2 \mathrm{mmol} / \mathrm{L})$, and glucose $(11.1 \mathrm{mmol} / \mathrm{L})$. All reagents were purchased from Sigma Aldrich Chemical Company (Poznan, Poland) and ticagrelor from AstraZeneca Company.

2.3. Study Design and Conduction. After dissection from surrounding tissues, 2.5 to $3.0 \mathrm{~cm}$ long segments of rat tail arteries were cannulated and connected to a perfusion device. The distal part was weighted with a $500 \mathrm{mg}$ weight, and the arteries were placed in a $20 \mathrm{~mL}$ container filled with oxygenated Krebs solution at $37^{\circ} \mathrm{C}$. The perfusion pressure was continuously measured. Perfusion solution flow was gradually increased up to $1 \mathrm{~mL} / \mathrm{min}$ using a peristaltic pump. Vessel contractions induced with phenylephrine (PHE), a full $\alpha_{1}$ adrenergic receptor agonist, in the presence of 2-MeSADP (a stable analogue of ADP, $10 \mu \mathrm{M} / \mathrm{L}$ ) were measured as an increase in perfusion pressure. The addition of the latter was a consequence of the results of previously published studies indicating that 2-MeS-ADP acts on VSMCs as a partial agonist $[10,11,17]$. The maximal effect after stimulation with $2-\mathrm{MeS}-\mathrm{ADP}$ corresponds to $50-60 \%$ of contraction evoked by $\alpha_{1}$ adrenergic receptors stimulation with $\mathrm{PHE}$ or to $60 \%$ of contraction induced by $\mathrm{KCl}(30 \mathrm{mM} / \mathrm{L})[10,11]$. Additionally, taking into consideration the reversible binding of the $\mathrm{P}_{2} \mathrm{Y}_{12}$ receptor by ticagrelor, its effects were assessed both in its presence $(1 \mu \mathrm{M} / \mathrm{L})$ and absence in the perfusion solution. Experiments were performed separately on control arteries and on arteries derived from rats pretreated with lowdose aspirin $(2 \mathrm{mg} / \mathrm{kg})$ or high-dose aspirin $(10 \mathrm{mg} / \mathrm{kg})$. The experiments were performed separately on arteries with and without vascular endothelium in order to assess the role of the vascular endothelium in regulation of vascular tone in arteries derived from rats pretreated with the investigated drugs (Figure 1). Successful endothelium removal was confirmed by vessel contraction in response to acetylcholine $\left(10^{-5} \mathrm{M} / \mathrm{L}\right)$.

2.4. Data Analysis and Statistical Procedures. Concentrationresponse curves (CRCs) were calculated according to the van Rossum method [18]. The maximal response of tissue $\left(E_{\max }\right)$ was calculated as a percent of the maximal response for PHE. Half maximal effective concentration $\left(\mathrm{EC}_{50}\right)$ was estimated using classical pharmacologic methods with $\mathrm{pD}_{2}$ the negative logarithm of the $\mathrm{EC}_{50}$. We used the number of the CRC and $E_{\text {max }}$ in all calculations estimating the statistical significance.

Results were presented as means \pm standard deviations. The Shapiro-Wilk test was used to determine normal distribution of the investigated variables. Statistical analysis was performed using the Newman-Keuls and ANOVA test for multiple comparisons of means. A two-sided difference was considered significant at $P<0.05$.

\section{Results}

3.1. Effect of High and Low Doses of Aspirin on the Contractility of VSMCs. CRCs calculated for arteries with endothelium 


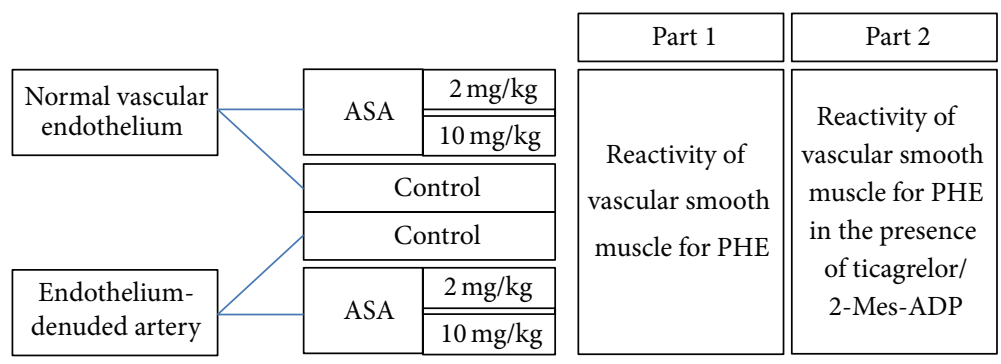

FIGURE 1: Flow diagram of study design.

TABLE 1: Maximal relative response for phenylephrine in relation to the presence of 2-MeS-ADP, ticagrelor and the dose of aspirin in arteries with vascular endothelium.

\begin{tabular}{|c|c|c|c|}
\hline & $n^{1}$ & $E_{\max }[\%]^{2}$ & $P$ \\
\hline Control rats: PHE $(10 \mu \mathrm{M} / \mathrm{L})$ & 20 & $99.0 \pm 2.4$ & \\
\hline $\begin{array}{l}\text { Ticagrelor pretreated rats: PHE }(10 \mu \mathrm{M} / \mathrm{L})+\text { ticagrelor }(1 \mu \mathrm{M} / \mathrm{L})+ \\
\text { 2-MeS-ADP }(10 \mu \mathrm{M} / \mathrm{L})\end{array}$ & 23 & $79.0 \pm 4.7$ & $P<0.0001^{\mathrm{a}}$ \\
\hline Low-dose aspirin pretreated rats: $\mathrm{PHE}(10 \mu \mathrm{M} / \mathrm{L})$ & 18 & $99.0 \pm 9.8$ & $\mathrm{~ns}^{\mathrm{a}}$ \\
\hline $\begin{array}{l}\text { Ticagrelor and low-dose aspirin pretreated rats: } \mathrm{PHE}(10 \mu \mathrm{M} / \mathrm{L})+\text { ticagrelor } \\
(1 \mu \mathrm{M} / \mathrm{L})+2-\mathrm{MeS}-\mathrm{ADP}(10 \mu \mathrm{M} / \mathrm{L})\end{array}$ & 18 & $79.0 \pm 11.4$ & $\begin{array}{c}P<0.0001^{\mathrm{a}} \\
P<0001^{\mathrm{b}} \mathrm{ns}^{\mathrm{c}}\end{array}$ \\
\hline High-dose aspirin pretreated rats: $\mathrm{PHE}(10 \mu \mathrm{M} / \mathrm{L})$ & 20 & $135.0 \pm 12.5$ & $P<0.0001^{\mathrm{a}}$ \\
\hline $\begin{array}{l}\text { Ticagrelor and high-dose aspirin pretreated rats: PHE }(10 \mu \mathrm{M} / \mathrm{L})+ \\
\text { ticagrelor }(1 \mu \mathrm{M} / \mathrm{L})+2 \text {-MeS-ADP }(10 \mu \mathrm{M} / \mathrm{L})\end{array}$ & 20 & $133.0 \pm 11.7$ & $\begin{array}{c}P<0.0001^{\mathrm{a}} \\
P<0.0001^{\mathrm{c}} \\
\mathrm{ns}^{\mathrm{d}}\end{array}$ \\
\hline
\end{tabular}

PHE: phenylephrine; 2-MeS-ADP: stable analogue of adenosine diphosphate; ${ }^{1}$ number of concentration-response curves used for calculations; ${ }^{2} E_{\text {max }}$ : calculated as a percent of maximal response for PHE; ${ }^{a} P$ value calculated versus controls; ${ }^{b} P$ value calculated versus PHE + low-dose aspirin; ${ }^{\mathrm{c}} P$ value calculated versus PHE + ticagrelor + 2-MeS-ADP; ${ }^{\mathrm{d}} P$ value calculated versus PHE + high-dose aspirin.

derived from rats pretreated with high-dose aspirin were shifted to the left of control with an increase in the maximal response, whereas CRCs obtained for arteries derived from rats pretreated with low-dose aspirin were comparable to control (Table 1, Figure 2). EC 50 values in arteries with vascular endothelium calculated for $\mathrm{PHE}$, for rats pretreated with low-dose aspirin and for rats pretreated with high-dose aspirin, were $7.34( \pm 0.8) \times 10^{-8} \mathrm{M} / \mathrm{L}, 7.33( \pm 1.4) \times 10^{-8} \mathrm{M} / \mathrm{L}(P$ $=\mathrm{ns}$ for comparison with controls-7.34 $\left.( \pm 0.8) \times 10^{-8} \mathrm{M} / \mathrm{L}\right)$ and $2.62( \pm 1.4) \times 10^{-8} \mathrm{M} / \mathrm{L}(P<0.0001$ for comparison with controls $\left.-7.34( \pm 0.8) \times 10^{-8} \mathrm{M} / \mathrm{L}\right)$, respectively. Corresponding $\mathrm{pD} 2$ values are presented in Figure 3.

When compared with endothelium-preserved vessels, CRCs for PHE in endothelium-denuded arteries were shifted to the left with a significant increase in the maximal response. Neither pretreatment with high nor low dose of aspirin caused any significant shift in comparison with controls obtained for arteries without vascular endothelium (Table 2, Figure 4). EC $\mathrm{E}_{50}$ values in arteries without vascular endothelium calculated for PHE, for rats pretreated with lowdose aspirin and for rats pretreated with high-dose aspirin, were $1.9( \pm 1.5) \times 10^{-8} \mathrm{M} / \mathrm{L}, 2.72( \pm 1.3) \times 10^{-8} \mathrm{M} / \mathrm{L}(P=$ ns for comparison with control arteries without vascular endothelium-1.9 $\left.( \pm 1.5) \times 10^{-8} \mathrm{M} / \mathrm{L}\right)$ and $2.32( \pm 0.9) \times$ $10^{-8} \mathrm{M} / \mathrm{L}(P=$ ns for comparison with control arteries without vascular endothelium-1.9 $\left.( \pm 1.5) \times 10^{-8} \mathrm{M} / \mathrm{L}\right)$, respectively. Corresponding pD2 values are presented in Figure 3.
3.2. Effect of Ticagrelor. The second part of our experiment compared CRCs for PHE $\left(10^{-9}-10^{-3} \mathrm{M} / \mathrm{L}\right)$ in the absence and in the presence of $2-\mathrm{MeS}-\mathrm{ADP}$ and ticagrelor. In arteries with vascular endothelium, CRCs recorded in the presence of 2-MeS-ADP and ticagrelor showed a rightward shift with a marked reduction in the maximal response, compared to control CRCs (Figure 2). $\mathrm{EC}_{50}$ calculated for $\mathrm{PHE}$ in the presence of 2 -MeS-ADP and ticagrelor $(2.35( \pm 0.9) \times$ $\left.10^{-7} \mathrm{M} / \mathrm{L}\right)$ was significantly higher than $\mathrm{EC}_{50}$ for controls $\left(7.34[ \pm 0.8] \times 10^{-8} \mathrm{M} / \mathrm{L} ; P<0.0001\right)$. The inhibitory effect of ticagrelor was maintained in arteries with endothelial lining pretreated with low-dose, but not high-dose, aspirin (Table 1, Figure 2). $\mathrm{EC}_{50}$ values calculated for PHE in the presence of 2MeS-ADP and ticagrelor in arteries pretreated with low- and high-dose aspirin were $2.03( \pm 0.8) \times 10^{-7} \mathrm{M} / \mathrm{L}(P<0.0001$ for comparison with experiments in the absence of ticagrelor$\left.7.33( \pm 1.4) \times 10^{-8} \mathrm{M} / \mathrm{L}\right)$ and $3.50( \pm 1.5) \times 10^{-8} \mathrm{M} / \mathrm{L}(P=\mathrm{ns}$ for comparison with experiments in the absence of ticagrelor$\left.2.62( \pm 1.4) \times 10^{-8} \mathrm{M} / \mathrm{L}\right)$, respectively. Corresponding $\mathrm{pD} 2$ values are presented in Figure 3.

In experiments employing endothelium-denuded vessels, we observed a significant reduction of the maximal effect of ticagrelor without any rightward shift of the concentrationresponse curve for phenylephrine for low-dose aspirin while any anticontractile effect of ticagrelor was absent for highdose aspirin (Table 2, Figure 4). $\mathrm{EC}_{50}$ values calculated for $\mathrm{PHE}$ in the presence of 2-MeS-ADP and ticagrelor in arteries 
TABLE 2: Maximal relative response for phenylephrine in relation to the presence of 2-MeS-ADP, ticagrelor and the dose of aspirin in arteries without vascular endothelium.

\begin{tabular}{|c|c|c|c|}
\hline & $n^{1}$ & $E_{\max }[\%]^{2}$ & $P^{3}$ \\
\hline Control rats: PHE $(10 \mu \mathrm{M} / \mathrm{L})$ & 20 & $132.0 \pm 14.6$ & \\
\hline $\begin{array}{l}\text { Ticagrelor pretreated rats: PHE }(10 \mu \mathrm{M} / \mathrm{L})+\text { ticagrelor }(1 \mu \mathrm{M} / \mathrm{L})+ \\
2 \text {-MeS-ADP }(10 \mu \mathrm{M} / \mathrm{L})\end{array}$ & 20 & $97.0 \pm 15.9$ & $P<0.0001^{\mathrm{a}}$ \\
\hline Low-dose aspirin pretreated rats: $\mathrm{PHE}(10 \mu \mathrm{M} / \mathrm{L})$ & 21 & $115.0 \pm 12.2$ & $\mathrm{~ns}^{\mathrm{a}}$ \\
\hline $\begin{array}{l}\text { Ticagrelor and low-dose aspirin pretreated rats: } \mathrm{PHE}(10 \mu \mathrm{M} / \mathrm{L})+\text { ticagrelor } \\
(1 \mu \mathrm{M} / \mathrm{L})+2-\mathrm{MeS}-\mathrm{ADP}(10 \mu \mathrm{M} / \mathrm{L})\end{array}$ & 21 & $90.0 \pm 13.7$ & $\begin{array}{c}P<0.0001^{\mathrm{a}} \\
P<0.0001^{\mathrm{b}} \\
\mathrm{ns}^{\mathrm{c}}\end{array}$ \\
\hline High-dose aspirin pretreated rats: $\mathrm{PHE}(10 \mu \mathrm{M} / \mathrm{L})$ & 21 & $125.0 \pm 12.1$ & $\mathrm{~ns}^{\mathrm{a}}$ \\
\hline $\begin{array}{l}\text { Ticagrelor and high-dose aspirin pretreated rats: PHE }(10 \mu \mathrm{M} / \mathrm{L})+ \\
\text { ticagrelor }(1 \mu \mathrm{M} / \mathrm{L})+2-\mathrm{MeS}-\mathrm{ADP}(10 \mu \mathrm{M} / \mathrm{L})\end{array}$ & 21 & $123.0 \pm 14.2$ & $\begin{array}{c}\mathrm{ns}^{\mathrm{a}} \\
P<0.0001^{\mathrm{c}} \\
\mathrm{ns}^{\mathrm{d}}\end{array}$ \\
\hline
\end{tabular}

PHE: phenylephrine; 2-MeS-ADP: stable analogue of adenosine diphosphate; ${ }^{1}$ number of concentration-response curves used for calculations; ${ }^{2} E_{\max }$ : calculated as a percent of maximal response for PHE; ${ }^{\mathrm{a}} \mathrm{P}$ value calculated versus controls; ${ }^{\mathrm{b}} \mathrm{P}$ value calculated versus PHE + low-dose aspirin; ${ }^{\mathrm{c}} P$ value calculated versus PHE + ticagrelor + 2-MeS-ADP; ${ }^{\mathrm{d}} P$-value calculated versus PHE + high-dose aspirin.

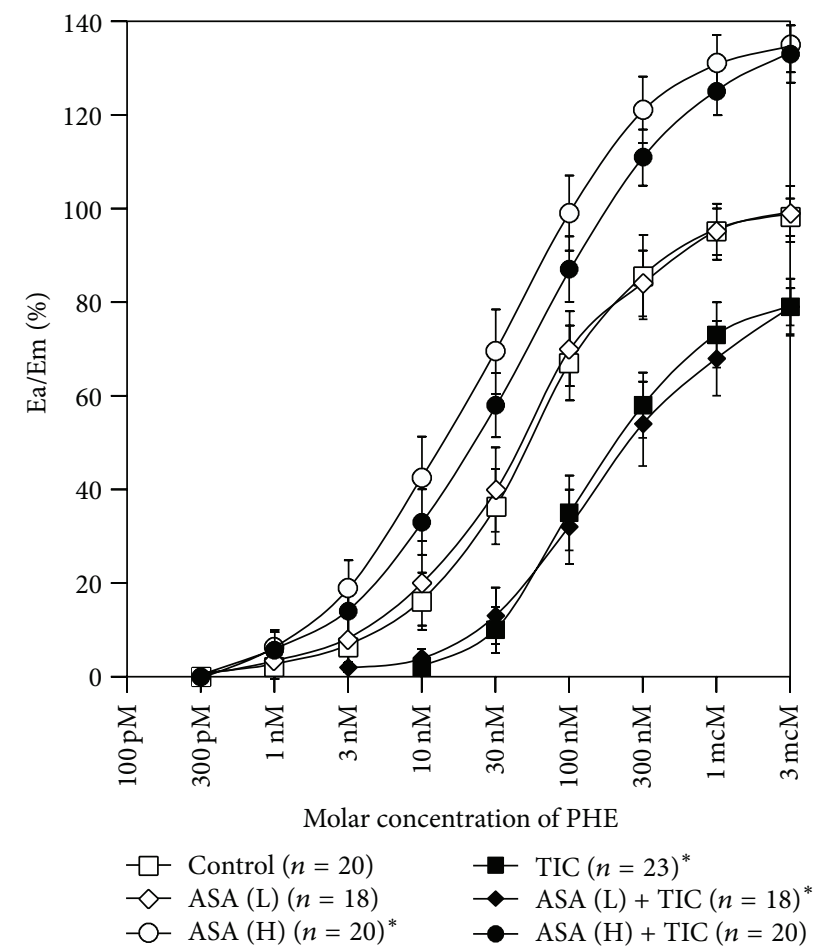

FIGURE 2: Concentration-response curves in arteries with vascular endothelium obtained for phenylephrine in the absence and presence of low-dose aspirin, high-dose aspirin, and ticagrelor coadministered with 2-MeS-ADP. Points and whiskers display mean values \pm standard deviations. A curve for PHE represents a control curve for TIC, ASA (L), and ASA (H) while curves for ASA (L) and ASA $(\mathrm{H})$ constitute control curves for ASA (L) + TIC and ASA (H) + TIC, respectively. ASA (H): high-dose aspirin; ASA (L): low-dose aspirin; $\mathrm{Ea} / \mathrm{Em}$ : \% of maximal response; PHE: phenylephrine; TIC: ticagrelor; 2-MeS-ADP: stable analogue of adenosine diphosphate; *a value of $P<0.05$ when comparing the control curve for points of effect between $20 \%$ and $80 \%$ of the maximal response.

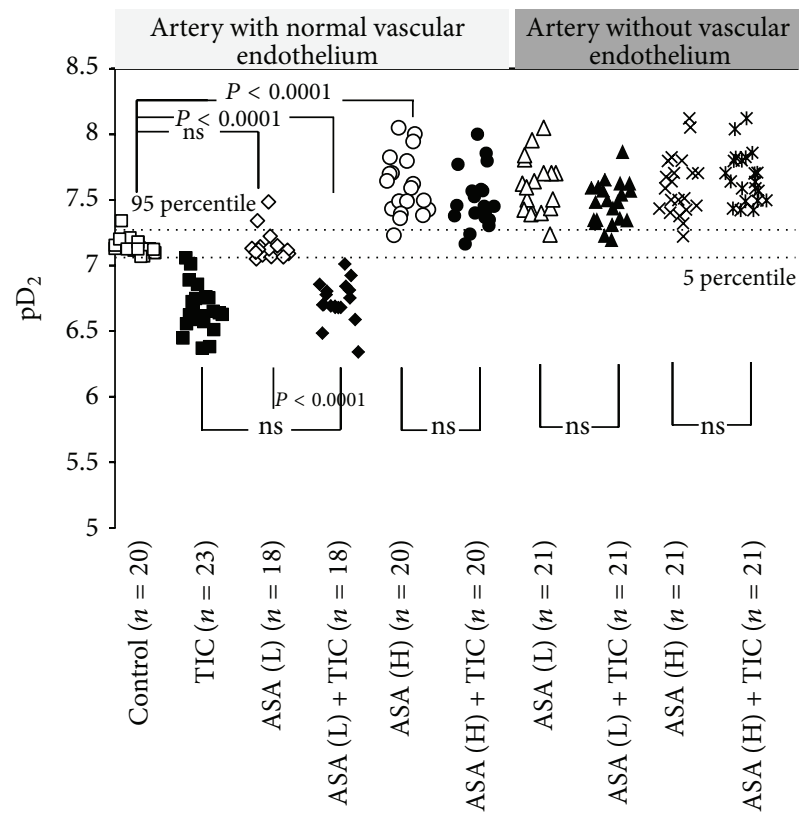

FIGURE 3: $\mathrm{pD}_{2}$ values in arteries with and without vascular endothelium obtained for phenylephrine in the absence and presence of low-dose aspirin, high-dose aspirin, and ticagrelor coadministered with 2-MeS-ADP. Measurements for phenylephrine alone represent controls. ASA (H): high-dose aspirin; ASA (L): low-dose aspirin; $\mathrm{Ea} / \mathrm{Em}$ : \% of maximal response; $\mathrm{EC}_{50}$ : molar concentration producing $50 \%$ of the maximal response; $\mathrm{pD} 2$ : negative logarithm of $\mathrm{EC}_{50}$; TIC: ticagrelor; 2-MeS-ADP: stable analogue of adenosine diphosphate.

pretreated with low-dose and high-dose aspirin were 3.58 $( \pm 1.3) \times 10^{-8} \mathrm{M} / \mathrm{L}(P=$ ns for comparison with experiments in the absence of ticagrelor $\left.-2.72[ \pm 1.3] \times 10^{-8} \mathrm{M} / \mathrm{L}\right)$ and 


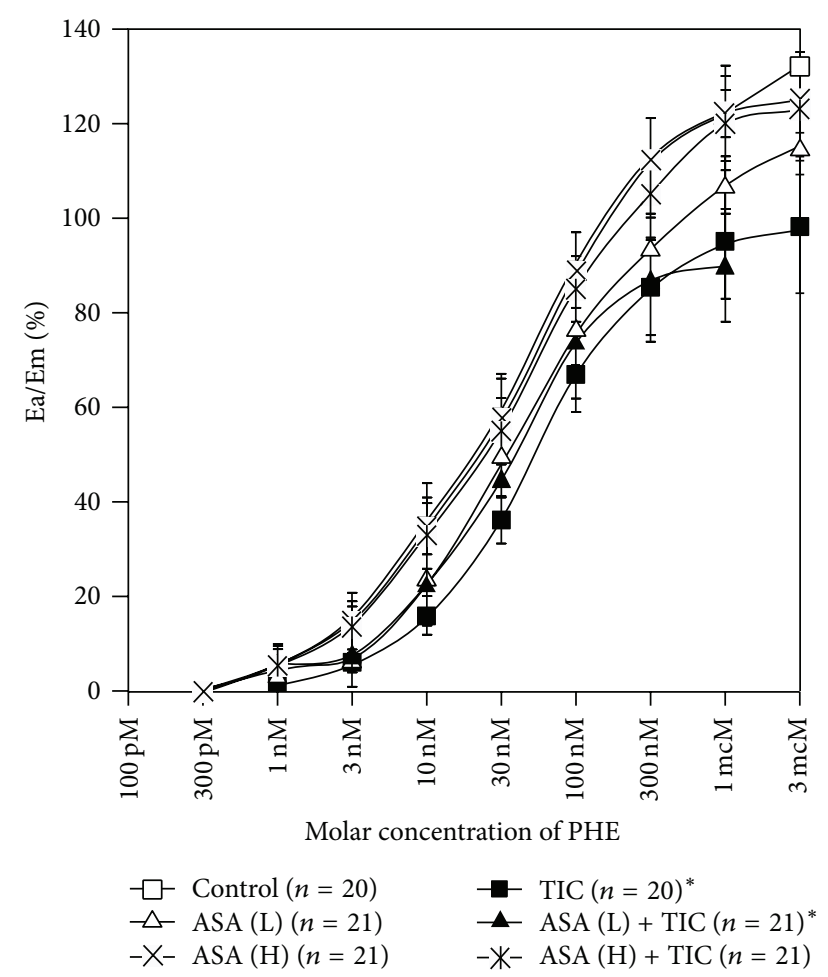

FIGURE 4: Concentration-response curves in arteries without vascular endothelium obtained for phenylephrine in the absence and presence of low-dose aspirin, high-dose aspirin, and ticagrelor coadministered with 2-MeS-ADP. Points and whiskers display mean values \pm standard deviations. A curve for PHE represents a control curve for TIC, ASA (L), and ASA (H) while curves for ASA (L) and ASA $(\mathrm{H})$ constitute control curves for ASA (L) + TIC and ASA (H) + TIC, respectively. ASA (H): high-dose aspirin; ASA (L): low-dose aspirin; Ea/Em: \% of maximal response; PHE: phenylephrine; TIC: ticagrelor; 2-MeS-ADP: stable analogue of adenosine diphosphate; * a value of $P<0.05$ when comparing the control curve for points of effect between $20 \%$ and $80 \%$ of the maximal response.

$2.81( \pm 1.3) \times 10^{-8} \mathrm{M} / \mathrm{L}(P=$ ns for comparison with experiments in the absence of ticagrelor $\left.-2.32[ \pm 0.9] \times 10^{-8} \mathrm{M} / \mathrm{L}\right)$, respectively. Corresponding $\mathrm{pD} 2$ values are presented in Figure 3.

\section{Discussion}

The main finding of the present study is that high-dose, but not low-dose, aspirin impairs the vasorelaxant effect of ticagrelor on the ADP-induced VSMC contraction in a rat model. This observation provides a new biologically plausible insight into our knowledge regarding the possible interaction between ticagrelor and aspirin doses (North American Paradox). Although the clinical relevance and detailed underlying mechanism of these findings are yet to be determined, coronary vasospasm is generally accepted to frequently accompany atherosclerotic plaque instability and thrombus formation while ADP constitutes an important secondary agonist released from activated platelets. ADP$\mathrm{P} 2 \mathrm{Y}_{12}$ interaction is suggested to be critical for the sustained activation of the glycoprotein GP IIb/IIIa receptor and stable platelet aggregation [4].

In the first part of our study we observed endotheliumdependent increased reactivity of VSMCs after pretreatment with high-dose, but not low-dose, aspirin. The concept linking therapy with nonsteroidal anti-inflammatory drugs (NSAIDs) with the risk of hypertension or worsening of preexisting hypertension has been known for almost 20 years $[19,20]$. Blood pressure is determined by peripheral resistance and cardiac output. The former depends on vascular tone while natriuresis intensity constitutes an important factor regulating the latter through changes in blood volume and subsequently in central venous pressure. Despite a clear association between NSAIDs use and rise in blood pressure, the relationship between aspirin and blood pressure is inconclusive [19-27]. A pooled analysis of five cohort studies demonstrated an $18 \%$ increase in the risk of hypertension among patients treated with aspirin [21] in contrast to the demonstration of an absence of influence of aspirin dose on blood pressure in two large meta-analyses [19, 20]; moreover, in two other studies, aspirin administered at bedtime lowered blood pressure [22, 23]. Another major confounding factor precluding any definitive conclusion is the range of aspirin doses utilized in the aforementioned studies. Finally, results of numerous trials are in general agreement such that treatment with low-dose aspirin influences neither blood pressure nor the efficacy of antihypertensive treatment [24-27]. Similarly, in our study pretreatment with low-dose aspirin was not associated with any elevation in the vascular tone.

The increased reactivity of VSMCs attributed to the administration of high-dose aspirin in our study may be caused by the inhibition of the prostanoid synthesis. NSAIDs, including aspirin, exert their therapeutic effects by inhibiting cyclooxygenase (COX). Aspirin is believed to exert its cardioprotective properties through irreversible inhibition of the platelet COX-1 isoform and subsequent prevention of the thromboxane $\mathrm{A}_{2}$ synthesis while the COX-2 isoform remains a target for classical NSAIDs [28]. However, aspirin, particularly at higher doses, can affect the production of other prostanoids in various tissues [28]. Prostacyclin acting through IP receptors exerts opposing biological effects as compared with thromboxane $\mathrm{A}_{2}$, including vasodilatation, suppression of VSMC proliferation, and inhibition of platelet activation. Prostaglandin $\mathrm{E}_{2}$ acts through multiple receptors, for example, $\mathrm{EP}_{1}, \mathrm{EP}_{2}, \mathrm{EP}_{3}, \mathrm{EP}_{4}$, and $\mathrm{IP}$, and its effects are more variable. In general, prostaglandin $\mathrm{E}_{2}$ tends to promote vasodilatation, while at low concentrations it increases platelet reactivity and at high concentrations inhibits platelet reactivity [28]. Inhibition of prostacyclin and prostaglandin $\mathrm{E}_{2}$ synthesis by aspirin may result in vasoconstriction and sodium and water retention, thus inducing hypertensive stimuli.

In line with our observations, Aldasoro et al. found that aspirin at high concentrations and nimesulide, a COX2 isoform selective inhibitor, potentiated the contractile response of gastroepiploic artery to both norepinephrine and vasopressin while low concentrations of aspirin or SC-560, a COX-1 isoform selective inhibitor, did not affect the responses 
of gastroepiploic artery $[29,30]$. Of interest, in other experimental studies, aspirin was simultaneously demonstrated to relax arterial vessels through an increased nitric oxide release from the porcine vascular endothelium by direct acetylation of endothelial nitric oxide synthetase. The latter effect is independent of COX inhibition [31] and through inhibition of PYK2-mediated RhoA/Rho-kinase activation [32].

In the second part of our study we observed that ticagrelor suppresses 2-MeS-ADP-induced VSMC contraction in arteries with and without endothelium. This fact corresponds with a previous report on the identification of $\mathrm{P}_{2} \mathrm{Y}_{12}$ receptors on VSMCs [9]. The inhibitory effect of ticagrelor was maintained in our study in arteries with endothelial lining pretreated with low-dose, but not high-dose, aspirin. In experiments employing endothelium-denuded vessels, low-dose aspirin treated animals showed a significant reduction of the maximal effect of ticagrelor without any rightward shift of the concentration-response curve for phenylephrine. However, in high-dose aspirin treated animals, ticagrelor evoked no anticontractile effect. Our results suggest that an impairment of the anticontractile effect of ticagrelor by high-dose aspirin and hyperreactivity of VSMCs after pretreatment with highdose aspirin are strongly influenced by the presence of endothelium. Since the vascular endothelium and VSMCs produce prostacyclin and, to a lesser extent, prostaglandin $\mathrm{E}_{2}$ under physiological conditions, we hypothesize that also the interaction between ticagrelor and high-dose aspirin observed in our study may be caused by inhibition of prostanoid synthesis. In line with our hypothesis, FitzGerald et al., using a wide range of aspirin doses, 20-2600 mg, proved that lower doses of aspirin possessed a greater inhibitory effect on thromboxane $A_{2}$ than prostacyclin metabolites, while increasing doses of aspirin suppressed excretion of both thromboxane $\mathrm{A}_{2}$ and prostacyclin metabolites in healthy volunteers [33]. Near-complete inhibition of thromboxane $\mathrm{A}_{2}$ production by low and high doses of aspirin together with a dose-dependent inhibition of the prostacyclin synthesis was confirmed in other studies of healthy controls or patients with atherothrombotic disease $[34,35]$. Additionally, intracoronary infusion of aspirin increased coronary vascular resistance and reduced coronary blood flow [36]. Detailed investigation revealed that intracoronary infusion of aspirin resulted in the attenuation of both pacing-induced coronary hyperaemia and flow-mediated coronary artery dilation [37]. Furthermore, recent studies demonstrated that genomic or pharmacological removal of prostacyclin activated both platelet-dependent and platelet-independent mechanisms inducing atherogenesis, promoting arterial remodelling, and triggering plaque instability and thrombosis [38, 39].

Recent data suggested that aspirin produces little enhancement of platelet inhibition in the presence of strong $\mathrm{P}_{2} \mathrm{Y}_{12}$ receptor blockade [40]. A recent study showed that ticagrelor is more potent than prasugrel active metabolite in this regard [41]. Ticagrelor may block the $\mathrm{P}_{2} \mathrm{Y}_{12}$-dependent pathway of platelet aggregation and also sufficiently inhibited platelet aggregation resulting from stimulation with arachidonic acid as suggested by Bhavaraju et al. [42]. Kirkby et al. suggested that in platelets the thromboxane $\mathrm{A}_{2}$-dependent pathway is dependent upon the ADP-P2Y 12 pathway both for the synthesis of thromboxane $\mathrm{A}_{2}$ and fundamentally for the irreversible aggregation that follows activation of the $\mathrm{TP}$ receptors [41]. It has been speculated that addition of aspirin to a potent $\mathrm{P} 2 \mathrm{Y}_{12}$ receptor antagonist may result in side effects secondary to inhibition of COX at nonplatelets sites, thus possibly increasing both bleeding, while providing little additional antiplatelet effects [41]. This concept is in line with the results of the PLATO trial where the occurrence of the primary end point was unrelated to aspirin maintenance dose in the clopidogrel arm [14] suggesting that high-dose aspirin does not offset the effect of clopidogrel, a moderate inhibitor of the $\mathrm{P} 2 \mathrm{Y}_{12}$ receptor. The question, whether aspirin provides any additional clinical benefit on top of ticagrelor, should be addressed in future randomized trials.

Our study has several limitations. First, as in all experimental studies, the relevance of the results needs verification in the clinical setting. Despite robust statistical techniques applied by Mahaffey et al., only a randomized study comparing the efficacy of ticagrelor and clopidogrel in relation to aspirin dose could provide a definitive answer. Second, in-depth determination of the mechanism involved in the impairment of the anticontractile effect of ticagrelor by highdose aspirin warrants further investigation. Third, we did not examine the impact of aspirin dosing on other off-target effects of ticagrelor as they may also contribute to the efficacy of ticagrelor therapy. Finally, the determination of equivalent drug exposures in the rat model versus clinically observed was approximated only.

In conclusion, high-dose, but not low-dose, aspirin impairs the anticontractile effect of ticagrelor on the ADPinduced VSMC contraction in an animal model. Both the clinical significance and detailed underlying mechanism of our findings require further investigation.

\section{Conflict of Interests}

Dr. Grzegorz Grześk and Dr. Marek Kozinski received honoraria for lectures from Astra Zeneca. Dr. Paul A. Gurbel received research grants, honoraria, and consultant fees from AstraZeneca and Bayer. The rest of the authors declare no conflict of interests.

\section{Authors' Contribution}

Grzegorz Grześk and Marek Kozinski have equally contributed to the present paper and should be considered first authors.

\section{Funding}

The study was funded from departmental sources.

\section{Acknowledgments}

The present contribution is a Project of Systematic Investigation and Research on Interventions and Outcomes (SIRIO), MEDICINE, a select group of senior scientists and fellows collaborating worldwide to pursue research and innovation in 
medicine. The authors are grateful to the staff of Department of Pharmacology and Therapeutics, particularly to Mrs. Lilianna Baran and Mrs. Małgorzata Golebiewska, for their outstanding technical support in the experiments.

\section{References}

[1] S. D. Wiviott, E. Braunwald, C. H. McCabe et al., "Prasugrel versus clopidogrel in patients with acute coronary syndromes," The New England Journal of Medicine, vol. 357, no. 20, pp. 20012015, 2007.

[2] L. Wallentin, R. C. Becker, A. Budaj et al., "Ticagrelor versus clopidogrel in patients with acute coronary syndromes," The New England Journal of Medicine, vol. 361, no. 11, pp. 1045-1057, 2009.

[3] E. P. Navarese, M. Verdoia, A. Schaffer et al., "Ischaemic and bleeding complications with new, compared to standard, ADPantagonist regimens in acute coronary syndromes: a metaanalysis of randomized trials," QJM, vol. 104, no. 7, Article ID hcr069, pp. 561-569, 2011.

[4] E. P. Navarese, A. Buffon, M. Kozinski et al., "A critical overview on ticagrelor in acute coronary syndromes," Quarterly Journal of Medicine, vol. 106, no. 2, pp. 105-115, 2013.

[5] P. G. Steg, S. K. James, D. Atar et al., "ESC guidelines for the management of acute myocardial infarction in patients presenting with ST-segment elevation: the Task Force on the management of ST-segment elevation acute myocardial infarction of the European Society of Cardiology (ESC)," European Heart Journal, vol. 33, no. 20, pp. 2569-2619, 2012.

[6] H. Jneid, J. L. Anderson, R. S. Wright et al., "2012 ACCF/AHA focused update of the guideline for the management of patients with unstable angina/Non-ST-elevation myocardial infarction (updating the 2007 guideline and replacing the 2011 focused update): a report of the American College of Cardiology Foundation/American Heart Association Task Force on practice guidelines," Journal of the American College of Cardiology, vol. 60, no. 7, pp. 645-681, 2012.

[7] P. A. Gurbel, K. P. Bliden, K. Butler et al., "Randomized double-blind assessment of the ONSET and OFFSET of the antiplatelet effects of ticagrelor versus clopidogrel in patients with stable coronary artery disease: the ONSET/OFFSET study," Circulation, vol. 120, no. 25, pp. 2577-2585, 2009.

[8] V. L. Serebruany, "Mortality benefit in PLATO cannot be explained by antiplatelet properties of ticagrelor," Cardiology, vol. 117, no. 3, pp. 231-233, 2011.

[9] A. Wihlborg, L. Wang, O. Ö. Braun et al., "ADP receptor P2Y12 is expressed in vascular smooth muscle cells and stimulates contraction in human blood vessels," Arteriosclerosis, Thrombosis, and Vascular Biology, vol. 24, no. 10, pp. 1810-1815, 2004.

[10] G. Grzesk, M. Kozinski, E. P. Navarese et al., “Ticagrelor, but not clopidogrel and prasugrel, prevents ADP-induced vascular smooth muscle cell contraction: a placebo-controlled study in rats," Thrombosis Research, vol. 17, no. 2, pp. 164-172, 2012.

[11] C. Högberg, H. Svensson, R. Gustafsson, A. Eyjolfsson, and D. Erlinge, "The reversible oral P2Y12 antagonist AZD6140 inhibits ADP-induced contractions in murine and human vasculature," International Journal of Cardiology, vol. 142, no. 2, pp. 187-192, 2010.

[12] J. J. van Giezen, J. Sidaway, P. Glaves, I. Kirk, and J. A. Björkman, "Ticagrelor inhibits adenosine uptake in vitro and enhances adenosine-mediated hyperemia responses in a canine model,"
Journal of Cardiovascular Pharmacology Therapy, vol. 17, no. 2, pp. 164-172, 2012.

[13] J. Öhman, R. Kudira, S. Albinsson, B. Olde, and D. Erlinge, "Ticagrelor induces adenosine triphosphate release from human red blood cells," Biochemical and Biophysical Research Communications, vol. 418, no. 4, pp. 754-758, 2012.

[14] K. W. Mahaffey, D. M. Wojdyla, K. Carroll et al., "Ticagrelor compared with clopidogrel by geographic region in the Platelet Inhibition and Patient Outcomes (PLATO) Trial," Circulation, vol. 124, no. 5, pp. 544-554, 2011.

[15] AstraZeneca, Brilinta REMS Document, NDA 22-433, 2011, http://www.fda.gov/NewsEvents/Newsroom/PressAnnouncements/ucm263964.htm.

[16] "Guide for the care and use of laboratory animals," Office of Science and Health Reports (NIH) 85-23, DRR/NIH, Bethesdo, Md,USA, 1985.

[17] F. R. C. Giachini, D. A. Osmond, S. Zhang et al., "Clopidogrel, independent of the vascular P2Y12 receptor, improves arterial function in small mesenteric arteries from AngII-hypertensive rats," Clinical Science, vol. 118, no. 7, pp. 463-471, 2010.

[18] J. M. van Rossum, "Cumulative dose-response curves. II. Technique for the making of dose-response curves in isolated organs and the evaluation of drug parameters," Archives Internationales de Pharmacodynamie et de Thérapie, vol. 143, pp. 299-330, 1963.

[19] J. E. Pope, J. J. Anderson, and D. T. Felson, "A meta-analysis of the effects of nonsteroidal anti-inflammatory drugs on blood pressure," Archives of Internal Medicine, vol. 153, no. 4, pp. 477484, 1993.

[20] A. G. Johnson, T. V. Nguyen, and R. O. Day, "Do nonsteroidal anti-inflammatory drugs affect blood pressure? A meta-analysis," Annals of Internal Medicine, vol. 121, no. 4, pp. 289-300, 1994.

[21] L. E. Bautista and L. M. Vera, "Antihypertensive effects of aspirin: what is the evidence?" Current Hypertension Reports, vol. 12, no. 4, pp. 282-289, 2010.

[22] R. C. Hermida, D. E. Ayala, C. Calvo, and J. E. López, "Aspirin administered at bedtime, but not on awakening, has an effect on ambulatory blood pressure in hypertensive patients," Journal of the American College of Cardiology, vol. 46, no. 6, pp. 975-983, 2005.

[23] R. C. Hermida, D. E. Ayala, C. Calvo et al., "Differing administration time-dependent effects of aspirin on blood pressure in dipper and non-dipper hypertensives," Hypertension, vol. 46, no. 4, pp. 1060-1068, 2005.

[24] V. Leinonen, J. Varis, R. Vesalainen, J. Päivärinta, M. Sillanpää, and I. Kantola, "Low-dose acetylsalicylic acid and blood pressure control in drug-treated hypertensive patients," European Journal of Cardiovascular Prevention and Rehabilitation, vol. 18, no. 1, pp. 136-140, 2011.

[25] F. Avanzini, G. Palumbo, C. Alli et al., "Effects of low-dose aspirin on clinic and ambulatory blood pressure in treated hypertensive patients," American Journal of Hypertension, vol. 13, no. 6, pp. 611-616, 2000.

[26] A. Zanchetti, L. Hansson, G. Leonetti et al., "Low-dose aspirin does not interfere with the blood pressure-lowering effects of antihypertensive therapy," Journal of Hypertension, vol. 20, no. 5, pp. 1015-1022, 2002.

[27] J. J. Nawarskas, R. R. Townsend, M. D. Cirigliano, and S. A. Spinler, "Effect of aspirin on blood pressure in hypertensive patients taking enalapril or losartan," American Journal of Hypertension, vol. 12, no. 8 I, pp. 784-789, 1999. 
[28] T. D. Warner, S. Nylander, and C. Whatling, "Anti-platelet therapy: cyclo-oxygenase inhibition and the use of aspirin with particular regard to dual anti-platelet therapy," British Journal of Clinical Pharmacology, vol. 72, no. 4, pp. 619-633, 2011.

[29] M. Aldasoro, M. D. Mauricio, E. Serna et al., "Aspirin and COX-2inhibitor nimesulide potentiate adrenergic contractions of human gastroepiploic artery," American Journal of Hypertension, vol. 20, no. 5, pp. 514-519, 2007.

[30] M. Aldasoro, M. D. Mauricio, E. Serna et al., "Effects of aspirin, nimesulide, and SC-560 on vasopressin-induced contraction of human gastroepiploic artery and saphenous vein," Critical Care Medicine, vol. 36, no. 1, pp. 193-197, 2008.

[31] D. Taubert, R. Berkels, N. Grosser, H. Schröder, D. Gründemann, and E. Schömig, "Aspirin induces nitric oxide release from vascular endothelium: a novel mechanism of action," British Journal of Pharmacology, vol. 143, no. 1, pp. 159-165, 2004.

[32] Z. Ying, F. R. C. Giachini, R. C. Tostes, and R. C. Webb, "Salicylates dilate blood vessels through inhibiting PYK2-mediated RhoA/Rho-kinase activation," Cardiovascular Research, vol. 83, no. 1, pp. 155-162, 2009.

[33] G. A. FitzGerald, J. A. Oates, and J. Hawiger, "Endogenous biosynthesis of prostacyclin and thromboxane and platelet function during chronic administration of aspirin in man," Journal of Clinical Investigation, vol. 71, no. 3, pp. 676-688, 1983.

[34] B. B. Weksler, S. B. Pett, and D. Alonso, "Differential inhibition by aspirin of vascular and platelet prostaglandin synthesis in atherosclerotic patients," The New England Journal of Medicine, vol. 308, no. 14, pp. 800-805, 1983.

[35] G. Davi, N. Custro, and S. Novo, "The effect of two low doses of aspirin on whole blood thromboxane and prostacyclin generation in healthy subjects," Thrombosis and Haemostasis, vol. 50, no. 3, pp. 669-670, 1983.

[36] S. J. Duffy, S. F. Castle, R. W. Harper, and I. T. Meredith, "Contribution of vasodilator prostanoids and nitric oxide to resting flow, metabolic vasodilation, and flow-mediated dilation in human coronary circulation," Circulation, vol. 100, no. 19, pp. 1951-1957, 1999.

[37] P. L. Friedman, E. J. Brown Jr., and S. Gunther, "Coronary vasoconstrictor effect of indomethacin in patients with coronaryartery disease," The New England Journal of Medicine, vol. 305, no. 20, pp. 1171-1175, 1981.

[38] R. D. Rudic, D. Brinster, Y. Cheng et al., "COX-2-derived prostacyclin modulates vascular remodeling," Circulation Research, vol. 96, no. 12, pp. 1240-1247, 2005.

[39] K. M. Egan, M. Wang, S. Fries et al., "Cyclooxygenases, thromboxane, and atherosclerosis: plaque destabilization by cyclooxygenase- 2 inhibition combined with thromboxane receptor antagonism," Circulation, vol. 111, no. 3, pp. 334-342, 2005.

[40] P. C. J. Armstrong, P. D. Leadbeater, M. V. Chan et al., "In the presence of strong P2Y12 receptor blockade, aspirin provides little additional inhibition of platelet aggregation," Journal of Thrombosis and Haemostasis, vol. 9, no. 3, pp. 552-561, 2011.

[41] N. S. Kirkby, P. D. M. Leadbeater, M. V. Chan, S. Nylander, J. A. Mitchell, and T. D. Warner, "Antiplatelet effects of aspirin vary with level of $\mathrm{P} 2 \mathrm{Y} 12$ receptor blockade supplied by either ticagrelor or prasugrel," Journal of Thrombosis and Haemostasis, vol. 9, no. 10, pp. 2103-2105, 2011.

[42] K. Bhavaraju, A. Georgakis, J. Jin et al., "Antagonism of P2Y12 reduces physiological thromboxane levels," Platelets, vol. 21, no. 8, pp. 604-609, 2010. 


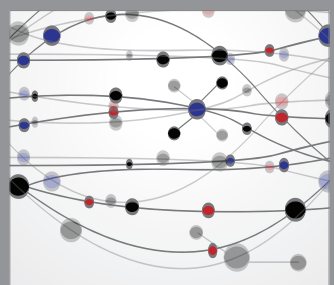

The Scientific World Journal
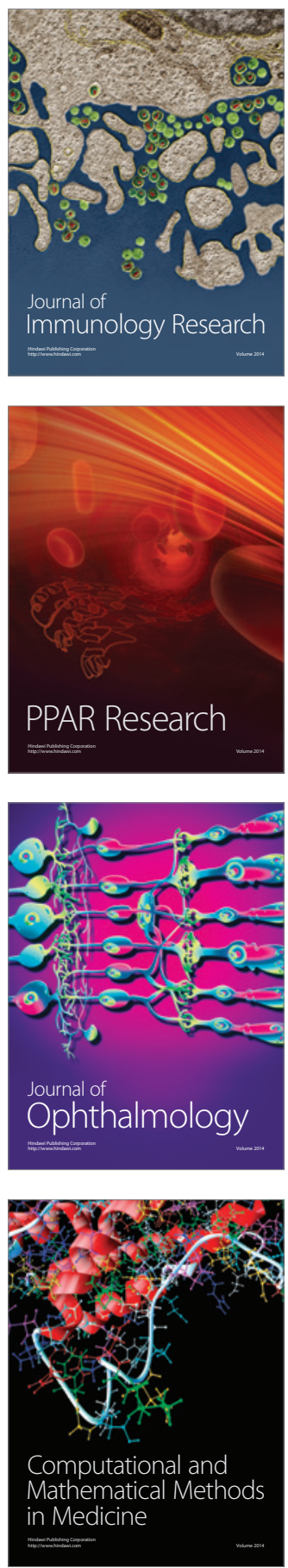

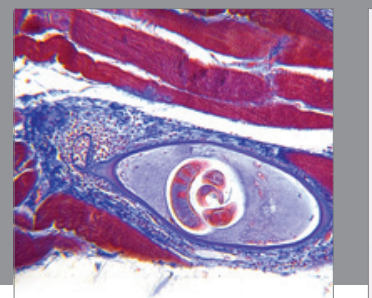

Gastroenterology

Research and Practice
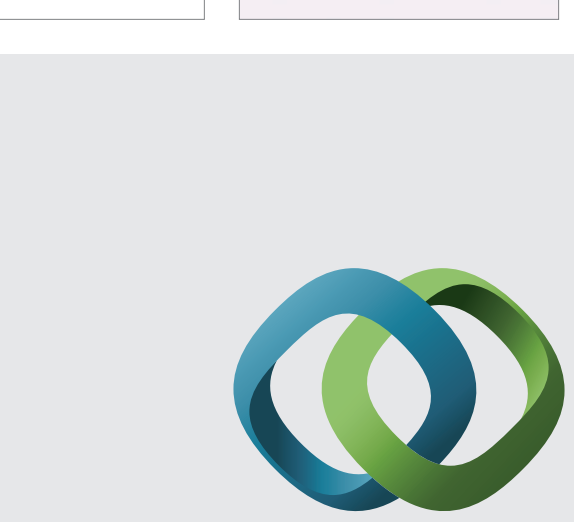

\section{Hindawi}

Submit your manuscripts at

http://www.hindawi.com
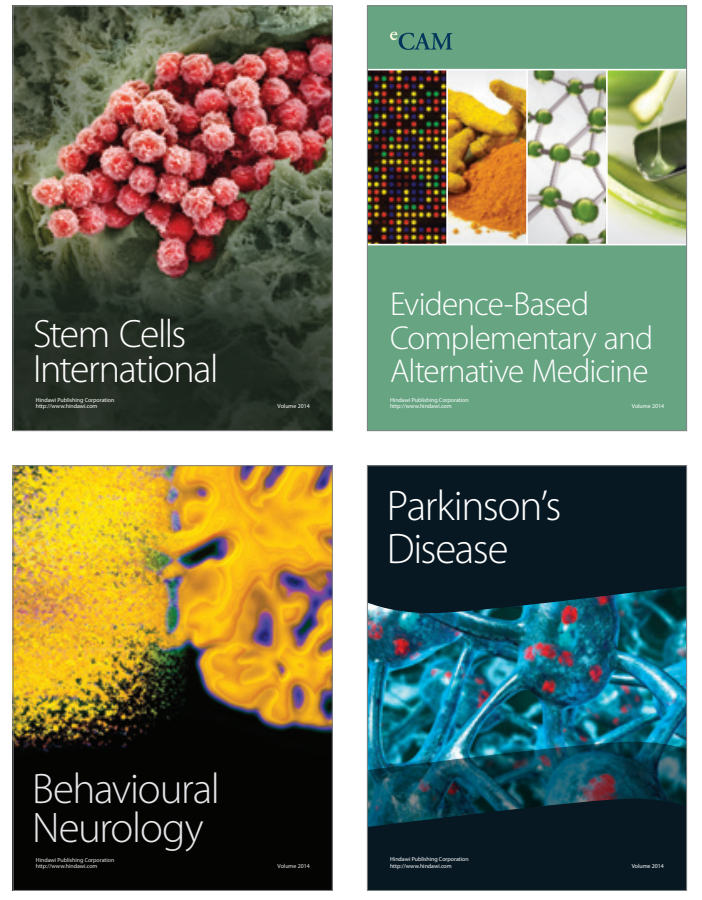
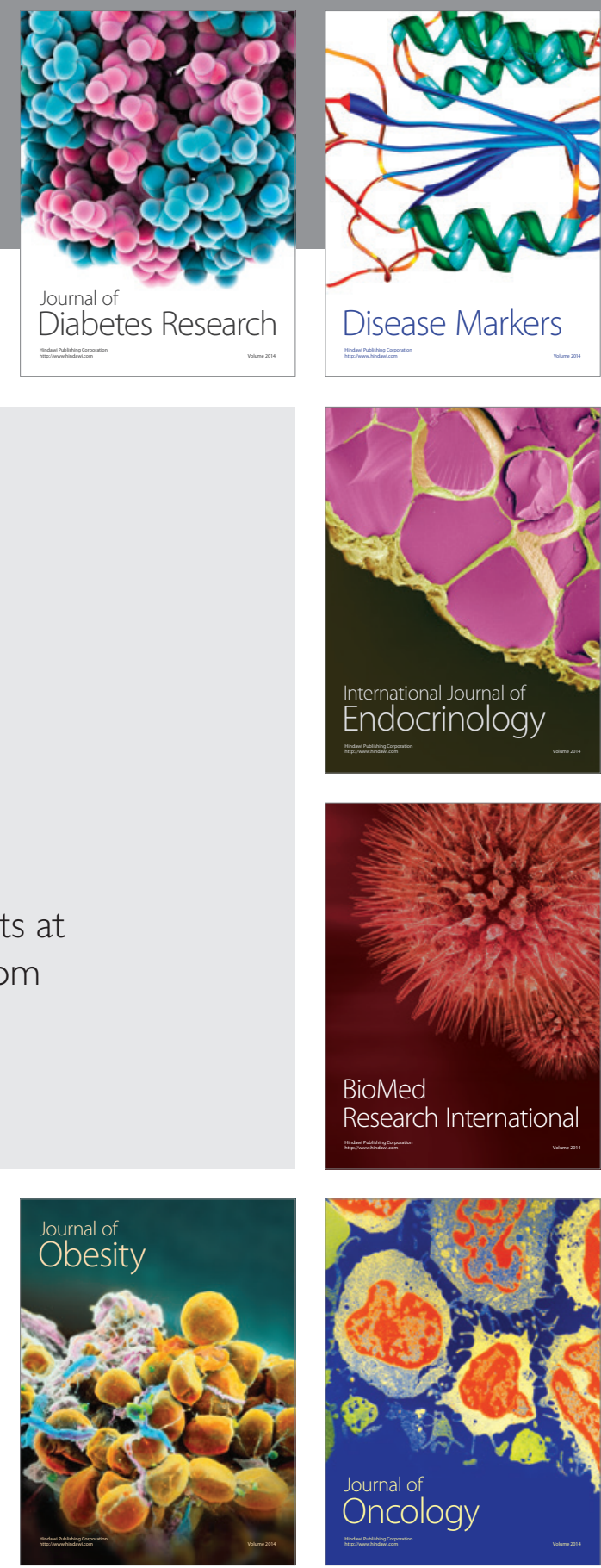

Disease Markers
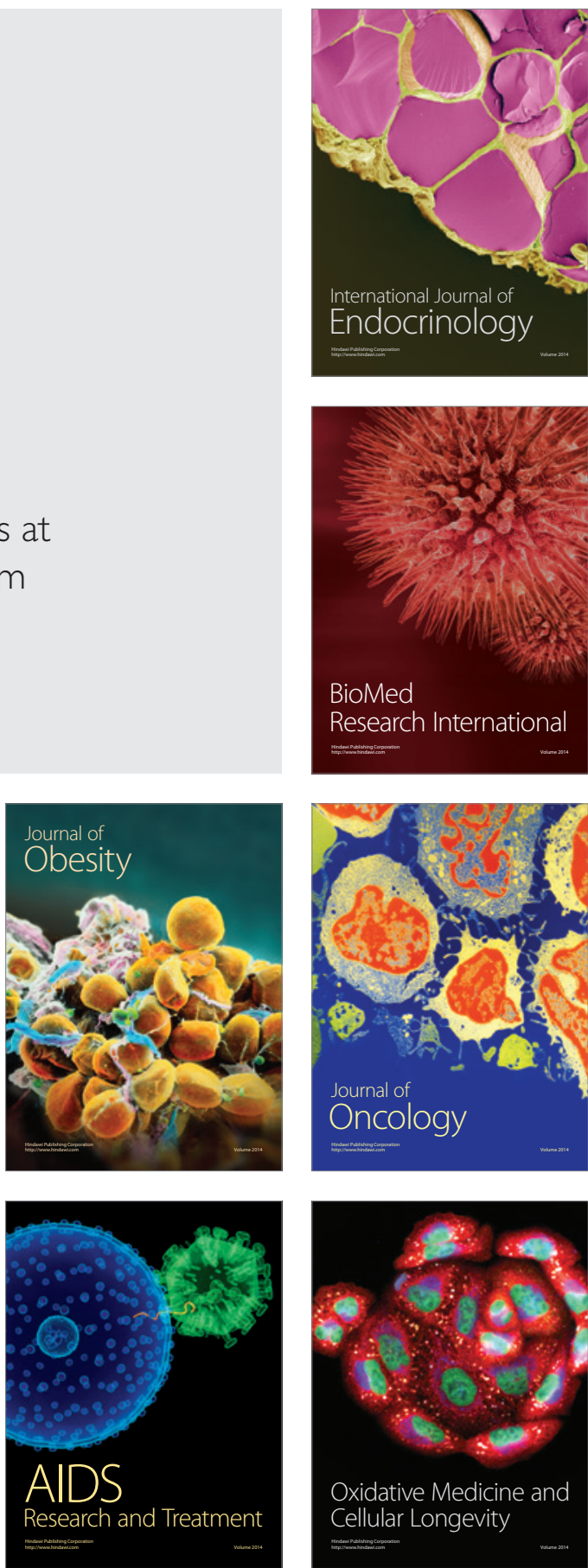